\begin{tabular}{c|l|l|l}
$\begin{array}{c}\text { Case Reports in } \\
\text { IeUlology }\end{array}$ & $\begin{array}{l}\text { Case Rep Neurol 2011;3:45-47 } \\
\text { DOl: 10.1159/000324179 }\end{array}$ & $\begin{array}{l}\text { Published online: } \\
\text { February 15, 2011 }\end{array}$ & $\begin{array}{l}\text { O 2011 S. Karger AG, Basel } \\
\text { ISSN 1662-680X } \\
\text { www.karger.com/crn }\end{array}$ \\
\hline
\end{tabular}

\title{
Gradenigo's Syndrome: Beyond the Classical Triad of Diplopia, Facial Pain and Otorrhea
}

\author{
José Luiz Pedroso ${ }^{a} \quad$ Camila Catherine Henriques de Aquino ${ }^{a}$ \\ Agessandro Abrahão ${ }^{a}$ Ricardo Araújo de Oliveira ${ }^{a}$ \\ Lauro Figueira Pinto ${ }^{a}$ Márcio Luis Escórcio Bezerra ${ }^{a}$ \\ Antonio Beuttenmuller Gonçalves Silva ${ }^{a}$ \\ Francisca Delanie Bulcão de Macedo ${ }^{b}$ \\ Ana Valéria de Melo Mendes ${ }^{\mathrm{b}}$ \\ Orlando Graziani Povoas Barsottini ${ }^{\mathrm{a}}$
}

Departments of aNeurology and Neurosurgery, and ${ }^{b}$ Medicine, Universidade

Federal de São Paulo, São Paulo, Brazil

\section{Key Words}

Gradenigo's syndrome · Non-Hodgkin's lymphoma · Petrositis · Cranial neuropathy

\begin{abstract}
We report a case of a non-Hodgkin's lymphoma in a young woman presenting with an abdominal mass and an unusual instance of cranial nerve palsies mimicking Gradenigo's syndrome. This condition is characterized by a triad of otorrhea, facial pain and diplopia, related to otitis media in the pre-antibiotic era. Incomplete and atypical clinical features of Gradenigo's syndrome have been described and noninfectious causes may mimic this condition. Careful clinical history and physical examination, including neuroimaging, are necessary to make a differential diagnosis.
\end{abstract}

\section{Introduction}

Gradenigo's syndrome (GS) was first described by Giuseppe Gradenigo in 1904 [1] when he reported a triad of symptoms consisting of periorbital unilateral pain related to trigeminal nerve involvement, diplopia due to sixth nerve palsy and persistent otorrhea, associated with bacterial otitis media with apex involvement of the petrous part of the temporal bone (petrositis). The classical syndrome related to otitis media has become very rare after the antibiotic era. Atypical cases of petrositis caused by cholesteatomas and chronic osteomyelitis of the petrous bone have been reported [2]. 


\section{Case Report}

A 33-year-old woman presented with a 3-week history of left facial palsy, diplopia and left-sided facial numbness. She also complained of nonspecific abdominal pain and persistent mild headache, but denied otorrhea, previous otitis media, fever and weight loss. She had smoked for 9 years. A palpable abdominal mass of about $20 \mathrm{~cm}$ was found in the right hypochondrium. Neurological examination showed palsies of the fifth, sixth and seventh left cranial nerves, with normal fundoscopy and no other focal deficit.

Laboratory tests showed mild elevated lactate dehydrogenase. Serological tests for HIV, hepatitis B and C, and syphilis were negative. Cerebrospinal fluid analysis showed no abnormalities. Brain MRI revealed an expansive gadolinium-enhanced lesion next to the petrous apex bilaterally and the nasopharynx (fig. 1). Abdominal CT scan revealed an irregular solid mass in the right kidney topography and retroperitoneal tissue. Biopsy of the abdominal mass showed a diffuse giant B-cell nonHodgkin's lymphoma and a nasopharyngeal mass corresponding to metastasis mimicking GS.

The patient was administered chemotherapy, with partial improvement of her symptoms. She is still in treatment.

\section{Discussion}

This case highlights some points beyond the classical triad of GS. First, clinical features in GS may be variable. In fact, in Gradenigo's original series of 57 patients, fewer than half presented with the complete triad. In other case series, involvements of the seventh and eighth cranial nerves were described [2].

Other tumors, such as nasopharyngeal carcinoma, have been reported mimicking GS [3]. A lymphoma which presented as GS was firstly reported in 1989 [4] and is still a rare condition. Primary non-Hodgkin's lymphoma of the petrous bone has also been reported [5]. On the other hand, a progressive afebrile clinical presentation without otological complaints secondary to infectious petrositis may be misdiagnosed as a tumor and delay antibiotic treatment [6].

In the GS diagnostic workup, MRI findings are superior to CT in differentiation between infection and neoplasia. Lymphomas and other neoplasias appear in MRI images as expansive lesions (hypointense on T1 and hyperintense on T2) with proeminent, diffuse and heterogeneous enhancement as shown in fig. 1. Infectious petrositis, too, shows hypointense $\mathrm{T} 1$ and hyperintense $\mathrm{T} 2$ images. In cases of abscess formation, a rim of gadolinium enhancement and diffusion-weighted imaging hyperintensity may be observed. Another cause of GS, cholesteatoma, appears as an expansive lesion with hypointense $\mathrm{T} 1$ and hyperintense $\mathrm{T} 2$ images without contrast enhancement. Osteomyelitis appears as a hypointense lesion on T1, discriminating from the normal fatty component of bone marrow, which has a high signal in T1-weighted image. Hyperintensity on T2-weighted images and gadolinium enhancement are also expected in osteomyelitis [7].

The objective of this report is to highlight that GS, as other multiple cranial nerve syndromes, may be caused by malignancies such as lymphoma, and should be extensively investigated to exclude other diagnoses. Physicians must be aware that neuroimaging has an essential role to differentiate among the possible etiologies. 


\begin{tabular}{r|l|l|l} 
Case Reports in & $\begin{array}{l}\text { Case Rep Neurol 2011;3:45-47 } \\
\text { DOI: } 10.1159 / 000324179\end{array}$ & $\begin{array}{l}\text { Published online: } \\
\text { February 15, 2011 }\end{array}$ & $\begin{array}{l}\text { @ 2011 S. Karger AG, Basel } \\
\text { ISSN 1662-680X } \\
\text { www.karger.com/crn }\end{array}$ \\
\hline
\end{tabular}
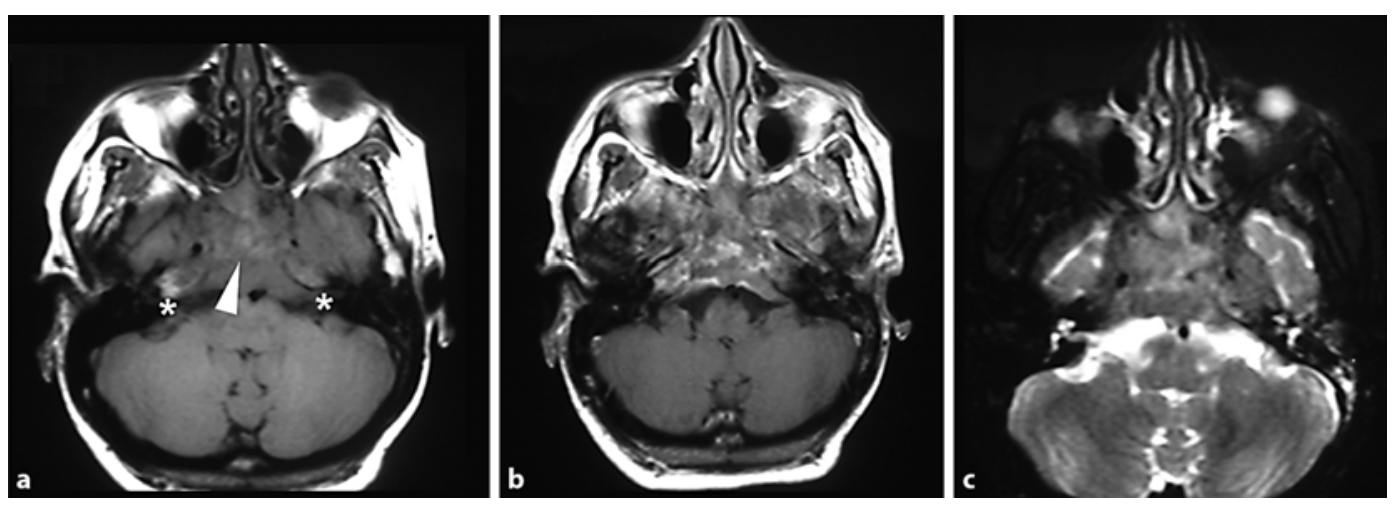

Fig. 1. Irregular solid mass (arrowhead) in the posterior nasopharyngeal space and petrous apex $\left(^{*}\right)$ bilaterally with heterogeneous signal in T1-weighted (a) and T2-weighted (c) axial MRI images. A prominent nonhomogeneous gadolinium enhancement is also observed (b).

\section{References}

$\longrightarrow 1$ Felisati D, Sperati G: Gradenigo’s syndrome and Dorello’s canal. Acta Otorhinolaryngol Ital 2009;29:169-172.

$\longrightarrow 2$ Sherman SC, Buchanan A: Gradenigo syndrome: a case report and review of a rare complication of otitis media. J Emerg Med 2004;27:253-256.

-3 Penas-Prado M, Diaz-Guzman J, Jimenez-Huerta I, Juntas-Morales R, Villarejo-Galende A, Diez-Torres I: Gradenigo syndrome as the form of presentation of nasopharyngeal carcinoma. Rev Neurol 2001;32:638-640.

4 Norwood VF, Haller JS: Gradenigo syndrome as presenting sign of T-cell lymphoma. Pediatr Neurol 1989;5:377-380.

5 Chang CY, O'Halloran EK, Fisher SR: Primary non-Hodgkin's lymphoma of the petrous bone: case report. Otolaryngol Head Neck Surg 2004;130:360-362.

6 Yoong HS, Kiaang TK: Gradenigo's syndrome presenting as a tumor. Otolaryngol Head Neck Surg 2006;135:821-822.

7 Ibrahim M, Shah G, Parmar H: Diffusion-weighted MRI identifies petrous apex abscess in Gradenigo syndrome. J Neuroophthalmol 2010;30:34-36. 